\title{
Patient Perceptions on Primary Health Care (PHC) Nurses and Its Impact on Services Delivery at County Level, Machakos, Kenya
}

\author{
Desire Aime Nshimirimana ${ }^{1, ~}$, Donald Kokonya ${ }^{2}$, Wanja Mwaura-Tenambergen ${ }^{1}$ \\ ${ }^{1}$ Department of Health Systems Management, School of Medicine \& Health Sciences, Kenya Methodist University, Nairobi, Kenya \\ ${ }^{2}$ Department of Mental Health, School of Medicine, Masinde Muliro University of Science \& Technology, Kakamega, Kenya
}

\section{Email address:}

desireaime.da@gmail.com (D. A. Nshimirimana), wanja.tenambergen@gmail.com (W. Mwaura-Tenambergen),

dkokonya@yahoo.com (D. Kokonya)

${ }^{*}$ Corresponding author

\section{To cite this article:}

Desire Aime Nshimirimana, Donald Kokonya, WanjaMwaura-Tenambergen. Patient Perceptions on Primary Health Care (PHC) Nurses and Its Impact on Services Delivery at County Level, Machakos, Kenya. Central African Journal of Public Health.

Vol. 5, No. 1, 2019, pp. 17-23. doi: 10.11648/j.cajph.20190501.13

Received: August 11, 2018; Accepted: December 4, 2018; Published: January 24, 2019

\begin{abstract}
Background: Patient perceptions on services delivered by nurses are crucial when assessing the quality of health services. These are most attributable to their knowledge, competent skills and other personal characteristics. These can be described in how effective they handle clients when performing their nursing duties and their effectiveness including their ability to utilize a variety of communication skills and their attitudes at their regular work place. Methodology: This is a crosssectional and qualitative study. Four public hospitals were randomly selected; Kathiani, Mwala sub-county hospital, Kangundo sub-district and Machakos county referral hospital. A systematic sampling was used for participant selection. A maximum of 12 and a minimum of 8 patients constituted a focus group for discussion (FGD) making a sample size of eighty (80) with eight (8) groups (four male and four female groups). The FGDs were conducted using standard guidelines by the researcher helped by a trained research assistant recording the proceedings with audio equipment. Participants aged 18-65 years and emancipated children were included. Data were analyzed using Atlas. ti 7 software. Results and Conclusion: (1) knowledge and competent skills of nurses, (2) personal characteristics, (3) other nurse's behaviors are key when to effectively perform nursing duties. Participants acknowledged that nurses have the same knowledge because they can be transferred from health centers to at hospital level. Other participants added that patients need nurses who can perform their work with confidence. Personal characteristics like positive attitude, good mood, smile and willingness to provide medical information were also discussed by participants as very important when nurses have to deliver quality health care services. Lastly, other nurse behaviors like respect, honesty, confidentiality and compassion are as well other crucial characteristics on the top of knowledge which were emphasized by participants. All discussed characteristics should link together if nurses have to deliver quality health care. Nursing schools should review their curriculum to include the characteristics mentioned and introduce mentorship programs where the emphasis should be placed on the same.
\end{abstract}

Keywords: PHC, Perceptions, Health Workers, Nurses, Patients

\section{Background}

Nursing profession dated back from 1853 with Florence Nightingale's involvement in caring for the Crimean War wounded. The nursing role in 1800's consisted of duties such as cleaning hospitals, general sanitation, and basic hygiene to patients. Today's nurse role has upgraded from hygiene and sanitation to that of a professional clinician, capable of combining technical, theoretical knowledge, expert clinical skills, empathy, and compassion for the delivery of competent patient care [1]. Patient perceptions on services delivered by nurses are crucial when assessing the quality of health services. Trust of patients towards health workers determines the willingness to consult or 
bypass a health facility [2]. Health services delivered by nurses are most attributable to their knowledge, competent skills and other personal characteristics. These can be described in how effective they handle clients when performing their nurse duties and their effectiveness including their ability to utilize a variety of communication skills and their attitudes at their regular work place [3]. Nurse ability to plan and organize their work will be of little benefit to clients if the attitudes that nurses are expected to demonstrate are not applied. It is very important for nurses to integrate knowledge, skills and attitudes as important components to perform their activities with competence [4]. Nursing role, responsibility and procedures play a big role in patient management for successful health outcomes. Nurse behaviour and attitudes are perceived by clients as important determinants to their satisfaction and the quality of health care services they expect. It is crucial for nurses to be knowledgeable about the caring behaviour as perceived by clients [5]. When nurses take care of their clients and show confidence, they feel treated and accepted as a unique person. When a nurse seems to exercise control and does not attach any importance to patients' views, they feel ignored and unable to follow advice. To achieve a successful nursing care, it is important that a nurse develop a personal, ordinary, and spontaneous approach in nursing practice [6]. Behavior, attitudes, provision of information related to care and perceived waiting time are among key elements considered when assessing patient satisfaction which translate to quality of nursing care delivery and is an important indicator for evaluation and improvement of health care services [7].Clients are considered to be a vital source of information for the evaluation of an existing care. In order to provide quality nursing care to clients, healthcare providers need to understand their perception as evidence of satisfaction to clients. Globally in the current competitive era, patient's perceptions about quality nursing care is becoming very important when assessing the nursing care [8]. Patients define quality with regard to interpersonal aspects of care, the way they are treated, and the promptness of the care provider while health care professionals define quality in relation to patient outcomes, standards of practice, and predetermined criteria used to measure quality [9]. Patient satisfaction is the perception of client needs and expectations being met. Level of satisfaction varies from person to person and service to service. The degree of satisfaction depends on a number of both psychological and physical variables which correlate with satisfaction behaviors such as return and recommend rate[10]. According to Ayyub et al.2015, positive attitude and smiling were identified to be of importance for patient's satisfaction and quality of care. He stressed that nurses have to keep a smile face even if tired because an angry face makes client low mood [9]. He continued and said that not only clinical skills and knowledge are factors contributing to quality but also a polite demeanor, smiling face and a good sense of humor also make significant impact on quality of primary health care nurses[11]. The most crucial elements nurses should provide for quality care services can be summarized in personal characteristics, information provision and competent clinical skills. Health care services should be available in a manner and language that is suitable to the community and population it serves and accommodating of local traditions and customs [12]. In Kenya, to my knowledge, no study on patient's perceptions at primary health care nurses has been done so far therefore this study comes as an evidence-based of a policy implementation on behavior change of nurses at primary health care [13]. The purpose of this study is to assess patient's perceptions of primary health care nurses that contribute to the functionality and satisfaction of successful gatekeeper system at county level, Machakos, Kenya.

\section{Methodology}

This study was conducted with approval of the Kenya Methodist University Ethical and research Committee (ERC) over a 3 month period from January to March 2015 among the public health facilities in Machakos County, Kenya. Four out of six public hospitals in Machakos County were selected to be parts of the study.

\subsection{Study Design}

This study is a cross-sectional and qualitative aimed at assessing patient's perceptions on quality of care of primary health care nurses at County level, Machakos, Kenya.

\subsection{Sampling Procedure and Sample Size Determination}

Among six public hospitals in Machakos County, four were selected randomly to be part of the study; Kathiani, Mwala sub-county hospital, Kangundo sub-district and Machakos county referral hospital previously known as level 5. A systematic sampling where every third client was selected to participate in the study but subject to inclusion and exclusion criteria was met. A maximum of 12 and a minimum of 8 patients constituted a focus group for discussion (FGD). For each hospital, 2 FGDs among patients and their care takers (by gender and age) were conducted. A number of 20 clients per hospital (10 male and 10 female clients) were selected, making a sample size of 80 for the entire study. The FGDs were conducted using the standard guidelines and a competently trained research assistant recording the proceedings of the FGDs and responses recorded on audio equipment to facilitate replay thereafter. All primary health care workers who had voluntarily signed the consent forms were included in the study and those who denied were excluded.

\subsection{Data Collection}

The FGDs were conducted using the standard guidelines by administration of questions by the researcher and a competent trained research assistant recording the proceedings of the FGD and responses recorded on audio equipment to facilitate replay thereafter. At each sub-county 
hospital, two FGDs were conducted, among patients and their caretakers. To facilitate data collection, the participants were divided in to 8 groups named group A, B, C, D, E, F, G and H where each group was formed by 10participants identified by numbers, from 1 to 10 .

\subsection{Inclusion and Exclusion Criteria}

All the study participants who were informed and had voluntarily signed their consent forms participated in this study and all adult participants aged 18-65 years and emancipated children responded to the questions. The emancipated children aged 15 years and above and fully responsible for the patients they accompanied to the health facilities qualified to participate in this study. All qualified and informed persons who have not voluntarily signed the consent forms were excluded; children below 15 years of age and adults above 65 years of age were excluded from this study. The study excluded the mentally incapable patients for purposes of data validity and integrity. Other exclusions were patients brought in as emergency cases, very sick and the critically ill.

\subsection{Data Management and Analysis}

The data were grouped first in three themes; knowledge and competent skills of nurses, personal characteristics and providing information and other nurses' behaviors (respect, honesty, compassion and confidentiality). Manual analysis was done for data on checklist after grouping them before transferring the groups to ATLAS.ti for further analysis. Literature search and references were done using Mendeley desktop.

\subsection{Study Limitations}

This study is qualitative and the results may not be generalizable and it has been done in one of the 47 Kenyan counties and therefore some similar studies in the rest of the counties are required to be able to generalize the results.

\section{Findings}

\subsection{Introduction}

The results of this study are divided in to 3 groups; (1) knowledge and competent skills of nurses; which are acquired at nursing schools supported by hospital practice, other trainings and workshops they do attend along their career whether for renewing practice licenses (in most countries, nurses renew their practice licenses on the basis of continuous medical education received yearly) or regular capacity building trainings from ministry of health or Non Governmental Organizations (NGOs) and other institutions. (2) Personal characteristics and providing information; these characteristics are not acquired at nursing school and this may be received from parents, life exposure or a result of family background. Managing patients is not only serving clients but need also a sense of humor, good mood and communication. (3) Other nurses' behaviors (respect, honesty, confidentiality and compassion); these are good behaviors patients discussed among others which are very important for nurses to perform their duties in an excellent way and this rewards satisfaction to clients. $50 \%$ of participants were male while $50 \%$ were female and age bracket was 18 to 65 years old in the focus group discussions.

\subsection{Patient Perceptions on Primary Health Care Nurses}

\subsubsection{Knowledge}

Participants discussed about their perceptions on primary health care providers about knowledge of nurses when they attend them; knowledge of nurses play a crucial role in patient's management as this is the baseline of trust and confidence of patients vise- a-vise nurses.

Client 5 in group D stated; "If nurses can be transferred from a health center to work in a hospital, it means they have the same knowledge both at health center and hospitals".

Client 5 in group E; "Some nurses are knowledgeable. We need nurses who have enough knowledge of their profession. When a nurse does what he/she knows, they do it with confidence and from there, they get trust from us (clients)".

Participants are aware of the knowledge of nurses and they know hospital and health center nurses receive the same training because they can be transferred from a health center to a hospital and this may not cause any trouble on patient management. Participants also recognized that nurses are knowledgeable and they can do their work with confidence.

\subsubsection{Competent Skills}

Skills are additional practical knowledge to practice their duties when attending clients. This refers to the ability and expertise to perform nursing skills and this is very important characteristic in patient management as these translate in to quality of nursing care.

Participant 6 in groupD;

"Nurses should have skills and competence to take care of our problems. Nurses who have enough skills and competence work professionally and when they perform procedures, the pain is minimal and increase trust and confidence and therefore the quality of care is felt".

Participant 8 in group F;

"On top of normal nursing school, we know nurses attend other trainings to boost their skills, we feel confident when we are treated by skilled and experienced nurse. It is very important that nurses acquire additional skills, it makes feel safe and confident".

Participant 8 group D; "if for example a nurse does not know how to insert a cannula to administer intravenous drugs, she will prick many times and this will lead to a painful procedure, and I will not be happy".

Participant 2groupE; " last month $i$ had a big wound and I came for change of dressing and the nurse did not give me a painkiller before doing the dressing, it was very painful and I did not like it". 
Participants discussed as well on the skills and competences of nurses which they believe are very important when nurses perform procedures because these make procedures easy to perform and the pain is less felt. They also believe that some nurses have such competence and it is advisable that all nurses acquire such competent skills to improve the quality of care.

\subsubsection{Personal Characteristics}

Good personal characteristics are not acquired at nursing school; this may be received from parents, exposure or a result of family background. They are very important in day to day life. This sub theme emerged from the participants' perceptions of good quality that nurses must possess in order to provide acceptable nursing care. Personal characteristics include positive attitudes like a smile face because an angry face makes other peoples' low mood.

Participant 2 groupA; "it is important that that nurses be polite and they should know that patients are always right, whatever patient says, nurses should actually accept it with a smile".

Participant 5 GroupB;"some nurses are very good and can smile with a good conversation when doing a procedure which make the patient feel comfortable and not feel pain".

Participant 9 in group D; "To be a patient can make you feel depressed, so you need a smiling nurse to help changing your mood so that you feel calm and happier"...

\subsubsection{Providing Information}

Nurses are supposed to provide clinical information and answer questions to patients related to procedures before and after performing a nursing procedure.

Participant 1 group C; "nurses should explain procedures before performing them. I came last month for a family planning procedure, and the nurse took me through the whole process and I felt very happy".

Participant 9 groupE; "one day I was admitted in maternity ward, waiting to deliver through cesarean section, the nurse explained me about the theatre procedure and i felt relaxed. Nurses know even how doctors 'procedures are done".

Participant2 groupF; "nurses explain also how to administer medication. I remember my daughter was sick and needed to be given medication through rectum every 6hours. The nurse took her time and explained in details how to administer and their side effects. This was a good one and I was happy".

Participants in the groups stressed the importance of giving information related to the procedures to perform, time to be taken and possible side effects. They appreciated that some nurses do provide information on the disease and the procedure to be performed. They also added that some nurses do not explain their procedures to patients. The recommendation given was that nurses should always provide information related to procedures to be performed as it can create trust, confidence and can influence the outcome of the procedure.

\subsubsection{Other Nurse Behaviors (Respect, Honesty, Confidentiality and Compassion)}

\section{i. Respect}

Respecting patients is one of the good behaviors of nurses. Respect can be seen by greeting and introducing him/herself to a client with courtesy and smile.

Participant 6 group F; "Some nurses don't respect patients, she/he can call you and will start injecting you drugs before even you know his/her name. Greeting a patient is the least a nurse can do before starting a procedure and this does not cost her/him anything".

Participant 4 group F; "last month I came to the hospital, a nurse who received me was very kind. She called me by my name, introduced herself and greeted me before asking for my details. I was happy"

Respect of patients is another characteristic which is not taught at nursing school but very important in the nursing career. Participants were very keen on the respect of nurses for example by introducing themselves to clients before performing any procedure. This opens the door to the client and makes him/her feel welcomed. In absence of respect, clients don't feel valued.

\section{ii. Honesty}

Health workers especially nurses have to be honest when providing patient information. Clients need to know with honesty what is going on so that they become trustfully.

Participant 2 group D: "Last year I had an appointment for an operation at the referral hospital and when I went, they postponed my program by giving me another appointment without explaining me the reason. I felt so bad".

Participant 1 group C: "One day I was injected a vaccine by a nurse and she did not informed me about the side effects, I was mad on her when I experienced these two days later".

Honesty was also discussed by participants as one of the personal characteristics which clients always appreciate. If a patient discovers a lie in the nurse's information then the whole facility is not trusted anymore. Nursing procedures built on honesty and trust become less painful and the quality of care is perceived.

\section{iii. Confidentiality}

Health workers are subjected to confidentiality for any information related to a patient seen in the facility. Revealing any patient information to another person without patient consent is unethical and this is punishable by the law.

Participant 8 group H; "In this hospital, nurses don't talk about other patient problems. They know that it is forbidden to them. Since 20years ago, I have been living in this town and $i$ have never heard any patient problem from a nurse".

Participant 2 group D; "In some facilities, nurses are not serious; they talk about patient's diseases and you can find nurses sited discussing a patient. I have heard them doing so in a hospital when i took my daughter last week and I did not like it".

Client 5 group A; 
"We also know that nurses have a high level of confidentiality. Once a nurse treats you, she/he cannot tell your problems to another person, they know how to keep secret".

Confidentiality makes clients feel that any health secret revealed them is not shared outside without their consent, otherwise patients may not give full information and this can lead to misdiagnosis or can also make clients reluctant to consult.

\section{iv. Compassion}

This is a sympathetic pity or concern for the sufferings of others. To serve well a suffering human being, it is very important to understand how others suffer or feel by putting yourself in someone's shoe.

Participant 4groupG; "one day I brought my son for immunization, and the nurse did not care about the pain my son felt".

Participant 5 group E; "Being a patient is a depressing feeling and in the hospital the environment should be in a way that favor patients and nurses should have some sense of compassion when treating patients"

Compassion is also one of the key characteristics of nurses if they are to deliver quality health services. When nurses place themselves in the patient's shoe, they are able to understand how others feel when they are sick and therefore handle them with care. This improves the quality of care.

\section{Discussion}

Patient perceptions of nurses at primary health care level are crucial for nursing services to be recognized as acceptable and satisfactory if quality of care need to be recognized. This is in line with patient expectations from nurses when they perform procedures. Nurses should have different characteristics to be able to deliver quality health care services and these are; knowledge, competent skills, personal characteristics, providing information and other nurses' behaviors mainly respect, honesty, confidentiality and compassion. According to previous studies, knowledge is the first intellectual property acquired at nursing school, before graduation, the faculty makes sure that nurses graduate with minimum knowledge which allow nurses to perform their duties [3]. Patients in the group discussions acknowledged that nurses have the basic knowledge to take care of their problems and other personal characteristics must complete theory. Clinical competence of nurses depend on their ability to link theoretical knowledge with practical clinical skills. Nursing theory alone cannot ensure quality of care without the application of practical skills in a respectful and confident manner. Translating theory in to practice therefore is crucial for the nursing profession. It is clear that the quality of clinical exposure plays a leading role in the development of nursing professionals[14]. The results of this study are similar to those of Ayyub et al. 2015. On the top of knowledge acquired at nursing school, competent skills are also recognized by participants as necessary and important component either gained with experience, exposure or acquired during trainings received along their nursing career. This potentiality gives them the ability to perform easily nursing procedures like branula's insertions, change of dressings, patient monitoring, and drug administration. Participants agreed that during those procedures, only nurses with experience and such characteristic can provide satisfaction to the patients as they contribute to less pain and confidence to nursing procedure. Nursing students acquire theoretical knowledge and translate it into professional roles which are needed in clinical field. They learn the art of nursing, which is crucial in nursing career [15]. It is very important that nurses learn to master the art of nursing through the acquisition of skills from clinical practice [16]. As a caring profession, nursing is a practical work in which the practitioner develops different skills such as psychomotor skills, cognitive thinking and affective skills, which are applied in the clinical situation [17]. To achieve effectively the nursing role, they have to combine theoretical knowledge, skills, values, beliefs and attitudes which form the foundation upon which nursing art is based on [18]. According to clients in the FGDs, the right nursing care practice is synonymous to the quality of care and quality of care is derived from quality of the theory learned, practical experience and mentorship which enhance professional competence [19]. The combination of theory and practice has an important role in the education of nursing students and influence the quality of care, competence and professional practice. If the theory learned is not translated in to practice, it becomes meaningless. In order to improve and maintain quality of care, new nurses should be assigned to experienced nurses for mentorship and supervision to help the new graduates translating theory in to practice and therefore provide safe and quality care. This study is similar to that of Oyetunde et al. (2014) in Nigeria where $68 \%$ of patients perceived that nurses were competent. Personal characteristics and providing information; On the top of knowledge and competent skills, other characteristics were discussed by participants during focus discussions. Positive characteristics are not acquired anywhere in the nursing training curriculum, they are either parts of family transmission, exposure or a result of family background. Patients are convinced that a nurse can be knowledgeable with competent clinical skills but if they don't have a human heart or a caring heart when dealing with sick peoples (i.e smiling, talking to patients with courtesy, responding to patient questions and sharing procedures information), this will not translate in to quality of care. Smiling and talking to patients with courtesy make patients feel good and friendly which increase the level of trust. On the other hand, sharing medical information and responding to patients questions remove doubt and increase confidence and trust [20].

\section{Conclusion}

Beside knowledge and skills acquired at nursing school, other human characteristics and behaviors are needed to 
provide quality nursing care. Personal characteristics including positive attitude, giving patient information and smiling face to the patients were also identified by participants as important personal additional characteristics. Other nurse behaviors such as respect, honesty, confidentiality and compassion have been also discussed at length in all focus group discussions, making them some very crucial characteristics which need to be looked into when it comes to deliver quality and acceptable nursing care. The linkage between the three themes makes nursing care comprehensive and best quality nursing care.

\section{Policy Implications}

The current study reflects the patients' opinions and not the actual performance of nurses. It gives important information regarding what nurses should be loaded with if they must deliver appropriate, acceptable and high standards nursing care services at primary health care in Machakos County. This study will be useful for health sector decision-makers if they are to review nursing curriculum for continuous improvement of the nursing training programs. Nursing training institutions should update their curriculums to suite client demands related to personal characteristics which are not acquired at nursing school.

\section{Author Contributions}

Desire Aime Nshimirimana is the main author who designed, drafted, discussed and reviewed the whole paper before submission. Donald Kokonya worked on methodology and discussion. He also polished the draft before publication. Wanja Mwaura Tenambergen worked on methodology and discussion of the findings.

\section{Competing Interest}

Authors declared no conflict of interest

\section{References}

[1] Fee, E., Garofalo, M. E., \& Chang, B. B. Florence nightingale and the crimean war. American Journal of Public Health, 2010100 (9), https://doi.org/10.2105/AJPH.2009.188607.

[2] Prakash B. Patient Satisfaction. Journal of Cutaneous and Aesthetic Surgery. 2010; 3 (3):151-155. doi:10.4103/09742077.74491.

[3] Babiker, A., El Husseini, M., Al Nemri, A., Al Frayh, A., Al Juryyan, N., Faki, M. O., ... Al Zamil, F. (2014). Health care professional development: Working as a team to improve patient care. Sudanese Journal of Paediatrics, 14(2), 9-16. Retrieved from http://www.ncbi.nlm.nih.gov/pubmed/27493399\%5Cnhttp://w ww.pubmedcentral.nih.gov/articlerender.fcgi?artid=PMC4949 805 .

[4] Hughes, R. Nurses at the "sharp end" of patient care the everydayness of errors. Patient Safety and Quality: An Evidence-Based Handbook for Nurses, 2008 1-30. https://doi.org/NBK2672 [bookaccession].

[5] Salmond, S. W., \& Echevarria, M. Healthcare Transformation and Changing Roles for Nursing. Orthopaedic Nursing, 201736(1), 12-25.

https://doi.org/10.1097/NOR.0000000000000308.

[6] Larsson, I. E., Sahlsten, M. J. M., Segesten, K., \& Plos, K. A. E. Patients' Perceptions of Nurses' Behaviour That Influence Patient Participation in Nursing Care: A Critical Incident Study. Nursing Research and Practice, 2011, 1-8. https://doi.org/10.1155/2011/534060.

[7] Sofaer, S., \& Firminger, K. Patient Perceptions of the Quality of Health Services. Annual Review of Public Health, 2005 26(1), 513-559.

https://doi.org/10.1146/annurev.publhealth.25.050503.153958.

[8] Iloh, G., Njoku, P., Amadi, A., Godswill-Uko, E., Ofoedu, J., \& Okafor, G. Satisfaction with Quality of Care Received by Patients without National Health Insurance Attending a Primary Care Clinic in a Resource-Poor Environment of a Tertiary Hospital in Eastern Nigeria in the Era of Scaling up the Nigerian Formal Sector Health In. Annals of Medical and Health Sciences Research, 2013 3(1), 31. https://doi.org/10.4103/2141-9248.109471.

[9] R, A., Z, K., J, D., \& R, R. Perceptions of Patients Regarding Quality Nursing Care (QNC) at a Tertiary Care Hospital, Karachi, Pakistan. Journal of Clinical Research \& Bioethics,20156(6), 1-5. https://doi.org/10.4172/21559627.1000254 .

[10] Ndambuki, J. The level of patients ' satisfaction and perception on quality of nursing services in the Renal unit, Kenyatta National Hospital Nairobi, Kenya. Open Journal of Nursing, 201313(June), 186-194.

https://doi.org/10.4236/ojn.2013.32025.

[11] Munyewende, P. O., Levin, J., \& Rispel, L. C. An evaluation of the competencies of primary health care clinic nursing managers in two South African provinces. Global Health Action,20169(1), 32486. https://doi.org/10.3402/gha.v9.32486

[12] Reyes, H., Hadley, L., \& Davenport, D. A Comparative Analysis of Cultural Competence in Beginning and Graduating Nursing Students, 2013.

[13] Diniz, I. A., Cavalcante, R. B., Otoni, A., \& Mata, L. R. F. da. Perception of primary healthcare management nurses on the nursing process. Rev Bras Enferm,201568(2), 206-213. https://doi.org/10.1590/0034-7167.2015680204i.

[14] McHugh, M., \& Lake, E. Understanding Clinical Expertise: Nurse Education, Experience, and the Hospital Context. Research in Nursing \& Health,201133(4), 276-287. https://doi.org/10.1002/nur.20388.Understanding.

[15] Jamshidi, N., Molazem, Z., Sharif, F., Torabizadeh, C., \& Najafi Kalyani, M. The Challenges of Nursing Students in the Clinical Learning Environment: A Qualitative Study. The Scientific World Journal, 2016, 1-7. https://doi.org/10.1155/2016/1846178.

[16] Baxter, C. A. The effect of coaching on nurse anager leadership of unit based performance improvement: exploratory case studies. DNP Practice Inquiry Projects, 2013 (3). Retrieved from http://uknowledge.uky.edu/dnp_etds/3. 
[17] Taylor, L. D. The affective domain in nursing education: Educators' perspectives. Theses and Dissertations, 2014 (151). Retrieved from http://search.ebscohost.com/login.aspx?direct=true $\& \mathrm{db}=\operatorname{cin} 20$ $\& \mathrm{AN}=109774671 \&$ site $=$ ehost-live

[18] Hudon, C., \& Fortin, M. Measuring patients' perceptions of patient-centered care: a systematic review of tools for family medicine. Journal of Family Medicine, 2011 155-164. https://doi.org/10.1370/afm.1226.
[19] van Graan, A. C., \& Williams, M. J. S. A conceptual framework to facilitate clinical judgement in nursing: A methodological perspective. Health SA Gesondheid, 2017 (22) 275-290. https://doi.org/10.1016/j.hsag.2017.01.004.

[20] Cónsul-Giribet, M., \& Medina-Moya, J. L. Strengths and weaknesses of Problem Based Learning from the professional perspective of registered nurses. Revista Latino-Americana de Enfermagem, 2014 22(5), 724-730.

https://doi.org/10.1590/0104-1169.3236.2473. 